\title{
PENDATAAN JENIS TUMBUHAN KOLEKSI KEBUN RAYA CIBODAS UNTUK MATERI PELAYANAN PENDIDIKAN LINGKUNGAN
}

\section{PLANT INVENTARIZATION OF CIBODAS BOTANICAL GARDEN COLLECTION TO ENRICH ENVIRONMENTAL EDUCATION SERVICES MATERIAL}

\author{
Muhammad Efendi*, Dwi Novia Puspitasari, Yetty Lestriani, Tatang \\ Balai Konservasi Tumbuhan Kebun Raya Cibodas - Lembaga Ilmu Pengetahuan Indonesia \\ Jl. Kebun Raya Cibodas, Cipanas, Cianjur, Jawa Barat telp/fax: +62 263512233
}

*Corresponding author: muhammadefendi05@gmail.com

\begin{abstract}
Abstrak
Program Pelayanan Pendidikan Lingkungan (Pepeling) merupakan implementasi fungsi Kebun Raya Cibodas (KRC) dalam bidang pendidikan, di mana kegiatan yang dilakukan adalah menyelenggarakan penyuluhan dan penanaman tumbuhan untuk instansi binaan KRC di Kabupaten Cianjur. Untuk memperkaya informasi jenis tumbuhan dalam Pepeling, pendataan potensi dan informasi lainnya perlu dilakukan. Tujuan penelitian ini untuk mendata jenis sekaligus potensi dari jenis-jenis tumbuhan yang dimanfaatkan dalam kegiatan Pepeling. Pengumpulan data menggunakan metode observasi, sedangkan potensi pemanfaatan jenis tumbuhan berdasarkan wawancara dan studi literatur. Berdasarkan hasil pengamatan, 106 jenis yang termasuk ke dalam 53 suku telah digunakan dalam kegiatan Pepeling. Tumbuhan tersebut berpotensi dimanfaatkan untuk obat, tanaman hias, pangan dan bibit tanaman hutan. Informasi teknik perbanyakan disajikan secara singkat dalam makalah ini.
\end{abstract}

Kata kunci: Kebun Raya Cibodas; Pendidikan Lingkungan; Status konservasi; Tumbuhan obat

\section{Abstract}

Environmental education program (abbreviated in Bahasa as Pepeling) is the implementation of Cibodas Botanical Garden (CBG) for education, which the activities undertook are organizing counseling and planting for the target institutions of CBG. In order to enrich information about which plant that used for Pepeling, potential data and other information are needed. The aims of this study are to record of the plant species in $C B G$ collection and their potential. Data was collected by a method of observation, while information of utilization was based on interviews and literature studies. The result showed that 106 species of 53 families have been used for the Pepeling activity, such as medicinal plants, ornamental plants, food and forest plants. Propagation information is shortly discussed in this paper.

Keywords: Environmental education; Cibodas Botanical Garden; Conservation status; medicinal plants

Permalink/DOI: http//:dx.doi.org/10.15408/kauniyah.v10i2.5209 


\section{PENDAHULUAN}

Kebun Raya Cibodas memiliki sejarah panjang dalam upaya kegiatan konservasi $e x$ situ tumbuhan hutan pegunungan Indonesia. Pada awal berdirinya, tahun 1852, Kebun Raya Cibodas dijadikan sebagai kawasan aklimatisasi tumbuhan yang penting dan bernilai ekonomi, salah satunya kina (Cinchona calisaya L.). Lebih lanjut, Kebun Raya Cibodas berkembang menjadi kawasan konservasi ex situ tumbuhan pegunungan khususnya kawasan Barat Indonesia. Sampai saat ini, Kebun Raya Cibodas telah mengoleksi sebanyak 11.002 spesimen, terutama jenis tumbuhan langka dan tumbuhan yang bernilai ekonomi (dapat diakses pada: http://sindata.krcibodas.lipi.go.id/CibodasBotanic-Gardens-Record/).

Jenis tumbuhan koleksi Kebun Raya Cibodas merupakan hasil eksplorasi di hutan Indonesia, pertukaran koleksi dengan kebun raya lain ataupun sumbangan. Koleksi tumbuhan tersebut ditata mengikuti pola klasifikasi taksonomi, bioregion, tematik atau kombinasi pola-pola tersebut untuk kegiatan konservasi, penelitian, pendidikan, wisata dan jasa lingkungan (Peraturan Presiden Nomor 93 tahun 2011).

Pelayanan Pendidikan Lingkungan (Pepeling) merupakan salah satu program Kebun Raya Cibodas untuk mendukung fungsi kebun raya dalam bidang pendidikan. Kegiatan yang dilakukan dalam kegiatan Pepeling antara lain penyuluhan, pengenalan tumbuhan koleksi dan penanaman tumbuhan hasil perbanyakan di Kebun Raya Cibodas. Sasaran kegiatan ini meliputi para siswa, kelompok tani dan ibu-ibu PKK di kawasan Kabupaten Cianjur. Sampai saat ini, sebanyak 245 instansi menjadi binaan Tim Pepeling Kebun Raya Cibodas.

Jenis tumbuhan yang digunakan dalam kegiatan Pepeling merupakan koleksi Kebun Raya Cibodas yang telah diperbanyak di Unit Pembibitan, Unit Pengembangan, dan Taman Tematik Tumbuhan Obat. Salah satu kegiatannya yakni penanaman. Jenis tumbuhan tersebut ditanam biasanya berupa koleksi tanaman obat (TOGA), tanaman hias maupun tanaman perindang. Jenis tumbuhan berperawakan pohon dan asli Jawa bagian Barat biasanya dijadikan sebagai tanaman penghijauan.
Makalah ini menyediakan informasi mengenai tumbuhan koleksi Kebun Raya Cibodas yang digunakan dalam kegiatan Pepeling selama lima tahun (tahun 2011 sampai dengan 2015). Informasi potensi pemanfaatan dan teknik perbanyakan tumbuhan yang telah dilakukan di Kebun Raya Cibodas disajikan secara singkat. Harapannya, data tersebut dapat memperkaya informasi dalam kegiatan Pepeling Kebun Raya Cibodas.

\section{BAHAN DAN METODE Pengumpulan data}

Jenis tumbuhan yang telah ditanam pada instansi binaan tim Pepeling Kebun Raya Cibodas didata dengan mengacu pada laporan kegiatan Pepeling antara tahun 2011 dan tahun 2015. Selain itu, jenis tumbuhan koleksi yang telah diperbanyak di Unit Pengembangan, Taman Tematik koleksi Tumbuhan Obat, dan Unit Pembibitan juga dicatat. Informasi pemanfaatan jenis dan teknik perbanyakan tumbuhan dilakukan melalui wawancara kepada 10 staf dari Unit Pengembangan, Taman Tematik koleksi Tumbuhan Obat, Unit Pembibitan, Unit Galeri dan Penjualan Kebun Raya Cibodas. Penentuan responden dilakukan secara purposive sampling karena tidak semua staf yang berada di Unit tersebut mengetahui tentang informasi yang dibutuhkan. Studi pustaka juga dilakukan untuk memperkaya informasi pemanfaatan jenis tumbuhan tersebut.

\section{Analisis data}

Data yang telah diperoleh, selanjutnya dianalisis secara deskriktif dan dikelompokkan berdasarkan taksa dan potensi pemanfaatannya.

\section{HASIL}

Berdasarkan hasil pengamatan, sebanyak 106 jenis tergolong ke dalam 53 suku tumbuhan yang dimanfaatkan untuk kegiatan Pepeling. Anggota suku Zingiberaceae paling banyak dimanfaatkan dalam kegiatan Pepeling, yakni sebanyak delapan jenis. Suku-suku berikutnya yaitu Acanthaceae, Cupressaceae, Lamiaceae dan Myrtaceae, masing-masing lima jenis.

Berdasarkan hasil wawancara, teknik perbanyakan tumbuhan yang banyak dilakukan untuk tumbuhan yang digunakan dalam kegiatan Pepeling menggunakan stek, terutama 
stek daun. Selain mendapatkan anakan yang sama dengan indukan, stek dinilai lebih cepat untuk mendapatkan anakan dalam jumlah yang banyak.

Potensi pemanfaatan tumbuhan koleksi sangat beragam. Jenis tumbuhan koleksi yang dimanfaatkan sebagai tanaman hias lebih banyak dibandingkan dengan pemanfaatan jenis tumbuhan lainnya. Hal ini banyak jenis tumbuhan yang berasal dari luar negeri sehingga penentuan nilai manfaat lebih banyak berdasarkan penampakan morfologi. Adapun nama jenis, potensi pemanfaatan dan teknik perbanyakan yang dilakukan di Kebun Raya Cibodas tersaji dalam Tabel 1.

Tabel 1. Jenis tumbuhan, potensi pemanfaatan dan teknik perbanyakan yang dimanfaatkan dalam kegiatan Pepeling

\begin{tabular}{|c|c|c|c|c|}
\hline No. & Nama ilmiah & Nama lokal & $\begin{array}{c}\text { Potensi } \\
\text { pemanfaatan }\end{array}$ & Perbanyakan \\
\hline \multicolumn{5}{|c|}{ Acanthaceae } \\
\hline 1. & Graptophyllum pictum (L.) Griff. & handeuleum & 1,2 & $\mathrm{~S}$ \\
\hline 2. & $\begin{array}{l}\text { Hemigraphis alternata (Burm.f.) T. } \\
\text { Anderson }\end{array}$ & remek getih & 1 & S \\
\hline 3. & Justicia gendarussa Burm.f. & gandarusa & 1 & S \\
\hline 4. & Staurogyne elongata Kuntze & rendeu & 1,3 & $S$ \\
\hline 5. & Strobilanthes crispus (L.) Bremek & keji beling & 1 & S \\
\hline \multicolumn{5}{|c|}{ Adiantaceae } \\
\hline 6. & Adiantum spp. & suplir & 2 & $\mathrm{~B}, \mathrm{P}$ \\
\hline \multicolumn{5}{|c|}{ Altingiaceae } \\
\hline 7. & Altingia excelsa Noronha & rasamala & 3,4 & B \\
\hline \multicolumn{5}{|c|}{ Annonaceae } \\
\hline 8. & Annona muricata $\mathrm{L}$. & sirsak & 1,3 & B \\
\hline \multicolumn{5}{|c|}{ Apiaceae } \\
\hline 9. & Centella asiatica (L.) Urb. & pegagan & 1,3 & $S$ \\
\hline \multicolumn{5}{|c|}{ Apocynaceae } \\
\hline 10. & $\begin{array}{l}\text { Allamanda cathartica L.H. Bailey } \\
\text { \& Raffill. }\end{array}$ & alamanda & 2 & $\mathrm{~S}, \mathrm{P}$ \\
\hline 11. & $\begin{array}{l}\text { Rauvolfia serpentina (L.) Benth. ex } \\
\text { Kurz }\end{array}$ & pule pandak & 2 & $\mathrm{~S}, \mathrm{~B}$ \\
\hline \multicolumn{5}{|c|}{ Araceae } \\
\hline 12. & Anthurium sp. & anthurium & 2 & $\mathrm{~S}, \mathrm{P}$ \\
\hline 13. & $\begin{array}{l}\text { Xanthosoma sagittifolium (L.) } \\
\text { Schott }\end{array}$ & talas hutan & 2 & $\mathrm{U}$ \\
\hline \multicolumn{5}{|c|}{ Araucariaceae } \\
\hline 14. & Agathis borneensis Warb. & damar & 4 & B \\
\hline 15. & $\begin{array}{l}\text { Araucaria cunninghamii Aiton ex. } \\
\text { D. Don }\end{array}$ & damar & 4 & $\mathrm{~S}, \mathrm{~B}$ \\
\hline \multicolumn{5}{|c|}{ Arecaceae } \\
\hline 16. & Pinanga javana Blume & pinang & 1,2 & B \\
\hline \multicolumn{5}{|c|}{ Asparagaceae } \\
\hline 17. & Agave sp. & agave & 2 & $\mathrm{~S}, \mathrm{P}$ \\
\hline & Cordyline stricta (Sims) Endl & hanjuang & 2 & $S$ \\
\hline 19. & Dracaena sp. & suji putih & 2 & $S$ \\
\hline $\begin{array}{l}20 . \\
\text { Aster }\end{array}$ & $\begin{array}{l}\text { Sansevieria } \mathrm{sp} . \\
\text { ceae }\end{array}$ & lidah mertua & 2 & S \\
\hline 21. & Pluchea indica (L.) Less. & beluntas & 1,3 & $\mathrm{~S}$ \\
\hline
\end{tabular}




\begin{tabular}{lccc}
\hline No. Nama ilmiah & Nama lokal & $\begin{array}{c}\text { Potensi } \\
\text { pemanfaatan }\end{array}$ & Perbanyakan \\
\hline
\end{tabular}

Basselaceae

22. Anredera cordifolia (Ten.) Steenis binahong

Berberidaceae

23. Berberis fortune Lindl.

24. Nandina domestica Thunb.

Bignoniaceae

25. Phyllarthron madagascariensis K. ki sendok 22 S, B

Schum.

\section{Boraginaceae}

26. Cordia sp.

ki koneng

nandina

1

S, B

2

S,B

\section{Brassicaceae}

27. Codiaeum variegatum (L.) Rumph. puring

komprey

4

S, C

$$
\text { ex. A. Juss. }
$$

\section{Bromeliaceae}

28. Bromelia spp.

29. Cryptanthus spp.

\section{Buxaceae}

30. Buxus sempervirens $\mathrm{L}$.

Cactaceae

31. Cereus hildmannianus K. Schum.

32. Echinocactus grusonii Hildm.

33. Mammillaria columbiana SalmDyck.

34. Rhipsalis sp.

\section{Casuarinaceae}

35. Casuarina equisetifolia L.

36. Casuarina junghuniana Miq.

\section{Cupressaceae}

37. Callitris rhomboidea $\mathrm{R}$. Br. ex Rich. \& A. Rich.

38. Cupressus arizonica Greene.

39. Cupressus cashmeriana Royle ex Carrière

40. Cupressus goveniana Gordon

41. Libocedrus formosana Florin

\section{Dilleniaceae}

42. Dillenia philippinensis Rolfe

Ericaceae

43. Rhododendron javanicum (Blume) Benn.

44. Rhododendron mucronatum (Blume) G. Don

45. Rhododendron sp.

Euphorbiaceae

46. Euphorbia pulcherrima Willd. Ex Klotzsch

47. Euphorbia tirucalli L.

48. Excoecaria cochinchinesis Lour.

49. Jatropha curcas L. bromelia

nanas-nanasan

buxus

kaktus

kaktus

kaktus

2

2

rhipsalis

2

S, B

cemara

cemara

4

4

cemara

4

cemara

2, 4

2, 4

S, B

cemara hujan

cemara

cemara

2,4

2

S, B

sempur

4

S, B, C

azelia

2

S, B

azelia

2

S, B

azelia

2

S, B

kastuba

2

patah tulang

sambang darah jarak
S

S

S

S

S

S, B

$\mathrm{S}$

B

B

B

S, B

S, B

$\mathrm{S}$

S

S 


\begin{tabular}{|c|c|c|c|c|}
\hline No. & Nama ilmiah & Nama lokal & $\begin{array}{c}\text { Potensi } \\
\text { pemanfaatan }\end{array}$ & Perbanyakan \\
\hline \multicolumn{5}{|c|}{ Fabaceae } \\
\hline 50. & Indigofera suffruticosa Mill. & tarum areuy & 2 & $\mathrm{~S}$ \\
\hline 51. & Intsia bijuga (Colebr.) Kuntze & - & 4 & $\mathrm{~S}, \mathrm{~B}$ \\
\hline 52. & $\begin{array}{l}\text { Castanopsis argentea (Blume) A. } \\
\text { DC }\end{array}$ & saninten & 4 & B \\
\hline \multicolumn{5}{|c|}{ Gesneriaceae } \\
\hline $\begin{array}{l}53 . \\
\text { Irida }\end{array}$ & $\begin{array}{l}\text { Aeschynanthus spp. } \\
\text { eae }\end{array}$ & bunga lipstik & 2 & $\mathrm{~S}$ \\
\hline 54. & $\begin{array}{l}\text { Eleutherine americana (Aubl.) } \\
\text { Merr. ex Heyne }\end{array}$ & bawang Dayak & 1 & $\mathrm{U}$ \\
\hline \multicolumn{5}{|c|}{ Lamiaceae } \\
\hline 55. & Clerodendrum serratum (L.) Moon & senggugu & 1,2 & $\mathrm{~S}, \mathrm{~B}$ \\
\hline 56. & $\begin{array}{l}\text { Plechtranthus scutellarioides (L.) } \\
\text { Benth. }\end{array}$ & jawer kotok & 2 & S \\
\hline 57. & Mentha $\mathrm{x}$ piperita $\mathrm{L}$. & $\operatorname{mint}$ & 1 & $\mathrm{~S}$ \\
\hline 58. & $\begin{array}{l}\text { Orthosiphon aristatus (Blume.) } \\
\text { Miq. }\end{array}$ & kumis kucing & 1,2 & $\mathrm{~S}$ \\
\hline & Vitex trifolia $\mathrm{L}$. & legundi & 1,5 & $\mathrm{~S}$ \\
\hline \multicolumn{5}{|c|}{ Lauraceae } \\
\hline 60. & $\begin{array}{l}\text { Cinnamomum burmanni (Ness.\& T. } \\
\text { Ness) Blume }\end{array}$ & kayu manis & 1,2 & $\mathrm{~B}$ \\
\hline & Cryptocarya laevigata Blume. & - & 4 & $\mathrm{~S}, \mathrm{~B}$ \\
\hline & Persea americana Mill. & alpukat & 3 & $\mathrm{~B}, \mathrm{Sa}, \mathrm{P}$ \\
\hline \multicolumn{5}{|c|}{ Lythraceae } \\
\hline & Cuphea sp. & - & 2 & $\mathrm{~S}$ \\
\hline $\begin{array}{l}64 . \\
\text { Mag }\end{array}$ & $\begin{array}{l}\text { Punica granatum L. } \\
\text { oliaceae }\end{array}$ & delima & 3 & $\mathrm{~B}, \mathrm{C}$ \\
\hline $\begin{array}{l}65 . \\
\text { Mart }\end{array}$ & $\begin{array}{l}\text { Magnolia blumei Prantl. } \\
\text { ataceae }\end{array}$ & cempaka & 1,2 & $\mathrm{~S}, \mathrm{~B}$ \\
\hline $\begin{array}{l}66 . \\
\text { Mela }\end{array}$ & $\begin{array}{l}\text { Maranta arundinacea } \mathrm{L} . \\
\text { tomataceae }\end{array}$ & patat & 2 & $\mathrm{P}$ \\
\hline $\begin{array}{l}67 . \\
\text { Morc }\end{array}$ & $\begin{array}{l}\text { Medinilla speciosa Blume } \\
\text { eae }\end{array}$ & harendong & 2 & $\mathrm{~S}, \mathrm{~B}$ \\
\hline $\begin{array}{l}68 . \\
M y r t\end{array}$ & $\begin{array}{l}\text { Ficus carica } \mathrm{L} . \\
\text { ceae }\end{array}$ & buah tin & 1,3 & $\mathrm{~S}, \mathrm{~B}$ \\
\hline 69. & Callistemon citrinus (Curtis) Skeel. & $\begin{array}{l}\text { bunga sikat } \\
\text { botol }\end{array}$ & 1,2 & $\mathrm{~S}, \mathrm{~B}$ \\
\hline 70 . & Plinia cauliflora (Mart.) Kausel & kupa landak & 1,2 & B \\
\hline 71. & Psidium araca Raddi & jambu brazil & 2,3 & $\mathrm{~B}$ \\
\hline & $\begin{array}{l}\text { Syzygium acuminatissimum } \\
\text { (Blume.) D.C }\end{array}$ & jambu & 1,2 & $\mathrm{~B}$ \\
\hline $\begin{array}{l}73 . \\
\text { Nym }\end{array}$ & $\begin{array}{l}\text { Syzygium myrtifolium Walp. } \\
\text { haeaceae }\end{array}$ & pucuk merah & 2 & $\mathrm{~B}$ \\
\hline $\begin{array}{l}74 . \\
\text { Olea }\end{array}$ & $\begin{array}{l}\text { Nymphaea sp. } \\
\text { eae }\end{array}$ & teratai & 2 & $S$ \\
\hline $\begin{array}{l}75 . \\
\text { Phyl }\end{array}$ & $\begin{array}{l}\text { Jasminum sambac (L.) Sol. } \\
\text { inthaceae }\end{array}$ & melati & 1,2 & $\mathrm{~S}$ \\
\hline & $\begin{array}{l}\text { Baccaurea racemosa (Reinw. ex } \\
\text { Blume) Müll.Arg. }\end{array}$ & kapundung & 3 & B \\
\hline
\end{tabular}




\begin{tabular}{|c|c|c|c|c|}
\hline No. & Nama ilmiah & Nama lokal & $\begin{array}{c}\text { Potensi } \\
\text { pemanfaatan }\end{array}$ & Perbanyakan \\
\hline 77. & Bridelia glauca Blume & ki pare & 4 & $\mathrm{~B}$ \\
\hline 78. & Sauropus androgynus (L.) Merr. & katuk & 1,3 & S, B \\
\hline \multicolumn{5}{|c|}{ Piperaceae } \\
\hline 79. & Piper betle L. & sirih & 1 & $S$ \\
\hline \multicolumn{5}{|c|}{ Plantaginaceae } \\
\hline & Plantago major L. & ki urat & 1,3 & $\mathrm{~B}$ \\
\hline \multicolumn{5}{|c|}{ Poaceae } \\
\hline 81. & Lophatherum gracile Brongn & tangkur gunung & 2 & $\mathrm{P}$ \\
\hline \multicolumn{5}{|c|}{ Podocarpaceae } \\
\hline 82. & $\begin{array}{l}\text { Dacrycarpus imbricatus (Blume) } \\
\text { de Laub. }\end{array}$ & cemara & 4 & B \\
\hline & Podocarpus imbricatus Blume & jamuju & 4 & $\mathrm{~S}, \mathrm{~B}, \mathrm{C}$ \\
\hline \multicolumn{5}{|c|}{ Primulaceae } \\
\hline 84. & Ardisia crenata Sims. & ardisia & 2 & $\mathrm{~B}$ \\
\hline \multicolumn{5}{|c|}{ Rosaceae } \\
\hline 85. & Prunus spp. & sakura & 2 & $\mathrm{~S}, \mathrm{C}$ \\
\hline & Rosa sp. & mawar & 2 & $\mathrm{~S}$ \\
\hline \multicolumn{5}{|c|}{ Rubiaceae } \\
\hline 87. & Gardenia jasminoides J. Ellis. & kaca piring & 1,2 & S, B \\
\hline & Gardenia thunbergia Thunb. & kaca piring & 2 & S, B \\
\hline & Ixora javanica (Blume.) D.C & soka & 2 & $\mathrm{~S}$ \\
\hline \multicolumn{5}{|c|}{ Schizaeaceae } \\
\hline & Lygodium sp. & paku hata & $1,2,5$ & B \\
\hline \multicolumn{5}{|c|}{ Schrphulariaceae } \\
\hline & $\begin{array}{l}\text { Ruselia equisetiformis Cham. \& } \\
\text { Schltdl. }\end{array}$ & $\begin{array}{l}\text { bunga air } \\
\text { mancur }\end{array}$ & 2 & $\mathrm{~S}$ \\
\hline \multicolumn{5}{|c|}{ Solanaceae } \\
\hline & $\begin{array}{l}\text { Brunfelsia pauciflora (Cham. \& } \\
\text { Schltdl.) Benth. }\end{array}$ & - & 2 & $S$ \\
\hline \multicolumn{5}{|c|}{ Taxaceae } \\
\hline 93. & Taxus sumatrana (Miq.) de Laub. & taxus & 1,5 & S \\
\hline \multicolumn{5}{|c|}{ Theaceae } \\
\hline 94. & Camellia japonica $\mathrm{L}$. & camellia & 2 & $\mathrm{~S}, \mathrm{Sa}$ \\
\hline & Schima wallichii Choisy & puspa & 4 & $\mathrm{~B}$ \\
\hline \multicolumn{5}{|c|}{ Thymelaeaceae } \\
\hline & $\begin{array}{l}\text { Phaleria macrocarpa (Scheff.) } \\
\text { Boerl. }\end{array}$ & mahkota dewa & 1 & $\mathrm{~S}, \mathrm{~B}$ \\
\hline \multicolumn{5}{|c|}{ Xanthorrhoeaceae } \\
\hline & Aloe vera (L.) Burm.f & lidah buaya & $1,2,5$ & $\mathrm{~S}, \mathrm{P}$ \\
\hline & Hemerocallis minor Mill. & - & 2 & $\mathrm{~S}$ \\
\hline \multicolumn{5}{|c|}{ Zingiberaceae } \\
\hline & $\begin{array}{l}\text { Alpinia malaccensis (Burm.f.) } \\
\text { Roscoe }\end{array}$ & laja goah & 1 & $\mathrm{U}$ \\
\hline 100. & Amomum cardamomum L. & kapol & 1 & $\mathrm{U}$ \\
\hline 101. & Curcuma aeruginosa Roxb. & koneng hideung & 1 & $\mathrm{U}$ \\
\hline 102. & Curcuma domestica Val. & kunyit & 1 & $\mathrm{U}$ \\
\hline 103. & Curcuma longa $\mathrm{L}$. & kunyit & 1 & $\mathrm{U}$ \\
\hline 104. & Curcuma xanthorrhiza Roxb. & temu lawak & 1 & $\mathrm{U}$ \\
\hline 105. & Curcuma zedoria Roxb. & kunyit putih & 1 & $\mathrm{U}$ \\
\hline
\end{tabular}




\begin{tabular}{llccc}
\hline No. & Nama ilmiah & Nama lokal & $\begin{array}{c}\text { Potensi } \\
\text { pemanfaatan }\end{array}$ & Perbanyakan \\
\hline 106. & Zingiber aromaticum Val. & lempuyang & 1 & $\mathrm{U}$ \\
\hline
\end{tabular}

Ket: 1). Obat, 2). Tanaman hias, 3). Pangan, 4). Tumbuhan hutan, 5). Pemanfaatan lainnya; S: stek, B: biji/spora, U: Umbi, Sa: Sambung pucuk, P: Pisah rumpun

\section{PEMBAHASAN}

Sebanyak delapan jenis anggota suku Zingiberaceae banyak dimanfaatkan dalam kegiatan Pepeling. Kandungan minyak atsiri pada Zingiberaceae dimanfaatkan sebagai obat, penyedap rasa, aroma makanan, minuman serta campuran pewangi dan kosmetik. Helaian daun juga dimanfaatkan sebagai pembungkus makanan dan bunganya untuk rujak terutama marga Etlingera (Heyne, 1987; Setyawan, 2003). Kandungan minyak atsiri ditemukan pada anggota suku Lamiaceae dan Myrtaceae yang dilaporkan oleh Handayani (2015a) sehingga berpotensi sebagai obat.

Pemanfaatan jenis tumbuhan sebagai obat secara tradisional oleh masyarakat di beberapa daerah Jawa Barat diantaranya rendeu, ki urat, handeleum, beluntas, sirih, bratawali, sirih, legundi, dan sambang darah (Handayani, 2015b; Ramdhan et al., 2015). Uji lanjutan pada skala laboratorium beberapa jenis tumbuhan telah dilakukan, antara lain kaca piring (Chaichana et al., 2009) dan beluntas sebagai antioksidan (Noridayu et al., 2011) dan remek getih sebagai anti bakteri (Rangheetha et al., 2016).

Tumbuhan dimanfaatkan sebagai tanaman hias biasanya didasarkan karakter bentuk, warna pada bunga dan helaian daun serta perawakannya. Jenis tumbuhan dengan warna bunga yang mencolok antara lain dari jenis begonia, mawar, ruselia, bunga ikat botol, alamanda, dan camellia sehingga menarik dijadikan sebagai tanaman hias. Jenis bunga lipstik dan azelia memiliki warna tepal yang mencolok dan bunga bentuk terompet, juga banyak dijadikan sebagai tanaman hias (Rahayu et al., 2015; Rahman, 2015). Aroma wangi pada bunga juga menjadi daya tarik tumbuhan sebagai tanaman hias, seperti pada melati dan magnolia.

Jenis tanaman yang dimanfaatkan sebagai pangan antara lain alpukat, jenis jambu terutama dari marga Syzygium dan Psidium, delima, buah tin dan sirsak dimanfaatkan sebagai tanaman buah. Pucuk muda daun rasamala, beluntas, antanan, ki urat dan rendeu dijadikan sebagai lalaban oleh masyarakat di sekitar Kebun Raya Cibodas. Selain itu, daun katuk dijadikan sebagai sayur. Kulit batang kayu manis dijadikan sebagai penyedap makanan.

Pemanfaatan tumbuhan sebagai bibit tanaman hutan lebih difokuskan pada jenis tumbuhan berperawakan pohon seperti puspa, rasamala, cemara hujan, jeruju dan damar. Jenis tumbuhan tersebut diperbanyak menggunakan biji untuk mendapatkan perakaran yang kuat. Jenis rasamala dan puspa merupakan jenis tumbuhan khas pegunungan Jawa bagian barat. Namun kini, kedua jenis tumbuhan tersebut sulit ditemukan pada hutan dengan ketinggian kurang dari $1.500 \mathrm{~m} \mathrm{dpl}$ (van Steenis, 2006).

Jenis tanaman untuk kegiatan Pepeling biasanya diperbanyak mengggunakan teknik stek terutama jenis tumbuhan herba, sukulen atau jenis tumbuhan yang sulit menghasilkan buah. Walaupun demikian, banyak jenis tumbuhan perdu berkayu yang juga juga diperbanyak menggunakan teknik stek dengan tambahan zat perangsang tumbuh akar. Teknik stek dilakukan untuk mendapatkan tanaman seragam, dalam jumlah banyak dan membutuhkan waktu relatif lebih cepat dibandingkan dengan biji.

Beberapa jenis tumbuhan asli Indonesia tergolong tumbuhan langka diantaranya jenisjenis Rhododendron (Rahman, 2008; Rahman \& Juariah, 2013). Berdasarkan data IUCN, jenis Agathis borneensis (Farjon, 2013), Taxus sumatrana yang juga dilaporkan sebagai anti kanker (Thomas \& Farjon, 2011) memiliki resiko kepunahan tinggi di alam. Selain itu, Podocarpus imbricatus (Thomas, 2013), Intsia bijuga (World Conservation Monitoring Centre, 1998) dan M. blumei (River, 2015) tergolong jenis yang kurang mendapatkan perhatian (least concern).

Kegiatan introduksi tumbuhan hasil perbanyakan tumbuhan koleksi penting 
dilakukan untuk menjaga keberadaan jenis tumbuhan bernilai ekonomi dan jenis tumbuhan langka, terutama jenis asli Indonesia (native spesies), sebagai salah satu fungsi dari tumbuhan koleksi tersebut. Selain itu, informasi potensi pemanfaatan dan teknik perbanyakan yang telah dilakukan di Kebun Raya Cibodas dapat diaplikasikan dalam masyarakat untuk pemanfaatan berkelanjutan terutama jenis-jenis tumbuhan yang bernilai ekonomi.

\section{KESIMPULAN}

Sebanyak 106 jenis tumbuhan dimanfaatkan untuk kegiatan Pepeling. Jenis tumbuhan tersebut tidak hanya digunakan sebagai tanaman hias, tetapi banyak jenis dapat dikembangkan sebagai tanaman obat, pangan dan tanaman hutan. Penyebarluasan informasi dan jenis tumbuhan perlu dilakukan untuk mempertahankan jenis tumbuhan terutama yang bernilai ekonomi maupun jenis tumbuhan langka.

\section{UCAPAN TERIMA KASIH}

Ucapan terima kasih kami sampaikan kepada rekan-rekan Tim Pelayanan Pendidikan Lingkungan Kebun Raya Cibodas yang telah membantu dalam mengumpulkan data penelitian ini.

\section{REFERENSI}

Chaichana, J., Niwatananun, W., Vejabhikul, S., Somna, S., \& Chansakaow, S. (2009). Volatile constituents and biological activities of Gardenia Jasminoides. Journal of Health Research, 23(3), 141145.

Farjon, A. (2013). Agathis borneensis. The IUCN Red List of Threatened Species 2013: e.T202905A2757743. http://dx.doi .org/10.2305/IUCN.UK.2013-1.RLTS.T 202905A2757743.en. Diakses tanggal 7 Maret 2017.

Handayani, A. (2015a). Keanekaragaman Lamiaceae berpotensi obat koleksi Taman Tumbuhan Obat Kebun Raya Cibodas, Jawa Barat. Prosiding Seminar Nasional Masyarakat Biodiversitas Indonesia, 1(6), September 2015, 13241327.

Handayani, A. (2015b). Pemanfaatan tumbuhan berkhasiat obat oleh masyarakat sekitar Cagar Alam Gunung Simpang, Jawa Barat. Prosiding Seminar Nasional Masyarakat Biodiversitas Indonesia, 1(6), September 2015, 14251432.

Heyne, K. (1987). Tumbuhan Berguna Indonesia I-IV. Jakarta: Sarana Wana Jaya. $2521 \mathrm{~h}$.

Noridayu, A. R., Hii, Y. F., Faridah, A., Khozirah, S. and Lajis, N. (2011). Antioxidant and antiacetylcholinesterase activities of Pluchea indica Less. International Food Research Journal, 18(3), 925-929.

Peraturan Presiden Republik Indonesia Nomor 93 tahun 2011 tentang Kebun Raya.

Rahayu, S., Wawangningrum, H. \& Garvita, R.V. (2015). Karakteristik morfologi dan perkembangan bunga Aeschynanthus tricolor Hook. (Gesneriaceae). Berita biologi, 14(3), 203-211.

Rahman, W. (2008). Kurang Data, status taksonomi, dan hybrid alami dalam konservasi Rhododendron spp. di Indonesia. Buletin Kebun Raya Indonesia, 11(2), 5-14.

Rahman, W. (2015). Kriteria penentuan spesies prioritas Rhododendron spp. terancam kepunahan untuk dikonservasi secara $e x$ situ di Indonesia. Buletin Kebun Raya, 18(1), 31-40.

Rahman, W., \& Juairiah, L. (2013). Evaluasi perkembangan dan pemanfaatan tanaman hias. Prosiding ekspose dan seminar pembangunan kebun raya daerah. Bogor, 25-26 November 2013.

Ramdhan, B., Chikmawati, T., \& Waluyo, E. B. (2015). Ethnomedical herb from Cikondang indigenous village, district Bandung West Java Indonesia. Journal of Biodiversity and Environmental Sciences (JBES), 277-288.

Rangheetha, R., Suganya, M., Sridharan, K., Sureshkumar, M., Vivekanandhan, G., Kalaiselvi, M., Bhuvaneshwari, V., \& Amsaveni, R. (2016). Evaluation of phytochemical constituents of Hemigraphis alternata (Burm.f.) T. Anderson leaf extract. Der Pharmacia Lettre, 8 (6), 335-338. 
Rivers, M. C. (2015). Magnolia sumatrana. The IUCN Red List of Threatened Species 2015: e.T66772941A66772945. http://dx.doi.org/10.2305/IUCN.UK.201 5-2.RLTS.T66772941A66 772945.en. Diakses tanggal 7 Maret 2017.

Rugayah, Retnowati, A., Windadri, F. I., \& Hidayat, A. (2004). Pengumpulan Data Taksonomi. Dalam Rugayah, Widjaja, E.A., \& Praptiwi (eds), Pedoman Pengumpulan Data Keanekaragaman Flora (hlm. 5-42). Bogor: Puslit Biologi LIPI.

Setyawan, D. A. (2003). Keanekaragaman kandungan minyak atsiri rimpang temutemuan (Curcuma). Biofarmasi, 1(2), 4449.

Thomas, P. (2013). Dacrycarpus imbricatus. The IUCN Red List of Threatened Species 2013: e.T42445A2980614. http://dx.doi.org/10.2305/IUCN.UK.201 3-1.RLTS.T42445A2980614.en. Diakes tanggal 2 Maret 2017.
Thomas, P. \& Farjon, A. (2011). Taxus wallichiana. The IUCN Red List of Threatened Species 2011: e.T46171879A9730085. http://dx.doi.org/10.2305/IUCN.UK.201 1-2.RLTS.T46171879 A9730085.en. Diakses tanggal 7 Maret 2017.

Van Steenis, C. G. G. J. (2006). Flora Pegunungan Jawa. Pusat Penelitian Biologi-LIPI. Bogor, $259 \mathrm{~h}$.

Widjaja, E. A., Rahayuningsih, Y., Rahayoe, J. S., Ubaidah, R., Maryanto, I., Walujo, E. B., \& Semiadi, G. (2014). Kekinian Keanekaragaman Hayati Indonesia 2014. LIPI Press. Jakarta, 344 h.

World Conservation Monitoring Centre. (1998). Intsia bijuga. The IUCN Red List of Threatened Species 1998: e.T32310A9694485. http://dx.doi.org/10.2305/IUCN.UK.199 8.RLTS.T32310 A9694485.en. Diakses tanggal 2 Maret 2017. 